\title{
O CORPO E A SEXUALIDADE EM A DOCE CANÇÃO DE CAETANA E EVA LUNA: REPRESENTAÇÕES DA DOMINAÇÃO E/OU DA LIBERTAÇÃO
}

\author{
Roseméri Aparecida Back ${ }^{1}$
}

\begin{abstract}
Resumo: Neste trabalho, procura-se evidenciar as representações do corpo e da sexualidade feminina nas obras A Doce Canção de Caetana (1987), de Nélida Píñon, e Eva Luna (1997), de Isabel Allende. O corpo é considerado uma marca de identificação de homens e mulheres e também como exercício de poder. $O$ foco principal é examinar aspectos do corpo subalterno, do corpo liberado, do corpo envelhecido e alguns pontos acerca da sexualidade. Primeiramente, realizou-se uma investigação sobre questões históricas e sociais que interferiram na condição feminina. Em seguida, discutiu-se algumas representações do corpo e da sexualidade, para então, analisar esses enfoques nas obras. Como referências foram usados os conceitos de Elódia Xavier, Michelle Perrot e Pierre Bourdieu.
\end{abstract}

Palavras-chave: Literatura, corpo feminino, sexualidade.

Abstract: In this work, we try to evidence the representations of the body and the feminine sexuality in the books A Doce Canção de Caetana (1987), of Nélida Píñon, and Eva Luna (1997), of Isabel Allende. The body is considered a mark of identification of men and women and also as exercise of power. The main focus is to examine aspects of the subordinate body, of the free body, the aged body and some points concerning about the sexuality. First, we inquiry about historical and social questions that had intervened in the feminine condition. After that, we argued some representations of the body and the sexuality, for then, to analyze these approaches in the books. As references, we used the concepts of Elódia Xavier, Michelle Perrot and Pierre Bourdieu.

Keywords: Literature, feminine body, sexuality.

O interesse por questões relativas à literatura de autoria feminina e a representação do corpo e da sexualidade da mulher são o ponto de partida para a execução deste trabalho. O corpo é visto como uma forma de identificação do feminino e do masculino, mas é especialmente tido como um estigma da representação do poder masculino. Em toda a história fica evidente a divisão entre o público, no que se refere aos papéis masculinos, e do privado, quanto aos papéis femininos. No século $\mathrm{XIX}$, a ação das mulheres era

\footnotetext{
${ }^{1}$ Mestranda em Literatura Comparada pela Universidade Regional Integrada do Alto Uruguai e das Missões (URI) - Campus de Frederico Westphalen. E-mail: rosemeriback@bol.com.br
} 
organizar o poder privado, familiar e materno. Entre os espaços sociais em que se apresenta, especialmente nas últimas décadas, o corpo feminino é reconhecido como objeto do olhar e do desejo.

Dessa forma, pretende-se examinar de que forma se dá a representação do corpo e da sexualidade feminina, a partir das obras A Doce Canção de Caetana, de Nélida Piñon, e Eva Luna, de Isabel Allende. A escolha deste corpus deve-se às convergências narrativas e intertextuais entre os dois textos, no que se refere às questões históricas e sociais e à representação do corpo e da sexualidade da mulher. Os estudos de Elódia Xavier, Michelle Perrot e Pierre Bourdieu são a base para esta análise.

Eva Luna é um romance escrito em 1987, pela chilena Isabel Allende. A obra é marcada pela ditadura no Chile, implantada com o golpe militar que, em 1973, derrubou o governo do primo do pai da escritora, o presidente Salvador Allende. Ele governou o país de 1970 a 1973. De 1973 a 1990, Augusto Pinochet assume o comando, período considerado o mais autoritário da história do país. Eva é fruto do subdesenvolvimento, do analfabetismo, da pobreza e de uma História muito conturbada. Eva não é só mais uma mulher, ela constrói um mundo com a memória e o resgata pela palavra.

A Doce Canção de Caetana, de Nélida Piñon, também foi escrito em 1987. Apresenta-nos os fatos que se desencadeiam em Trindade, uma pequena cidade do interior do Brasil, no começo dos anos 70, durante o governo do general Médici e da Copa do Mundo no México. Caetana, a protagonista, é uma atriz que, depois de vinte anos, volta a Trindade, resgatando sentimentos, sonhos e desencontros, principalmente do seu amante Polidoro, personagem que se constitui a partir da visão patriarcal e do poder político e econômico. Caetana retorna com seus amigos mambembes para realizar o seu sonho: viver Maria Callas no palco, imitando a ópera La Traviata. Além de Caetana, há outras personagens femininas com presença marcante na narrativa: as prostitutas, batizadas Três Graças e a cafetina Gioconda.

Michelle Perrot (2003), renomada historiadora e professora francesa, intitula uma de suas contribuições aos estudos femininos "Os silêncios do corpo da mulher". Nesse texto, ela analisa as formas de representação do 
corpo feminino na França; mas que podem ser aplicadas também a um contexto latino-americano e nas obras em estudo. Segundo ela, o corpo da mulher pode ser comparado ao corpo do rei: no espaço privado ele deve permanecer oculto; no público ele é exibido e está impregnado de significação.

Uma mulher em público pode ser somente uma figura que ostenta a fortuna do marido, "No palco do teatro, nos muros da cidade, a mulher é o espetáculo do homem. Muito cedo a publicidade soube combinar sua imagem à do produto elogiado" (PERROT, 2003, p. 14). Ainda hoje é assim. Também era símbolo político no século XIX, quando rechearam as cidades europeias com estátuas de heróis coroados com suas musas. No entanto, no contexto particular, o silêncio se faz presente também na intimidade da mulher, como por exemplo, nas transformações do corpo, em que a puberdade é um encaminhamento para a reprodução. Muitas vezes não há um diálogo entre mãe e filha acerca do sexo ou da menstruação. A partir da menopausa, a mulher passa a ser vista como um ser privado de fecundidade, mas principalmente, de sedução. Quanto à vida sexual, o prazer feminino é negado, ou até mesmo reprovado por ser coisa de prostitutas.

Araújo (2002) afirma que, historicamente, a lgreja sempre exerceu forte influência acerca da sexualidade feminina. A ideia era abafar qualquer manifestação sexual da mulher, pois a libertação ameaçava o equilíbrio, tanto social quanto doméstico. A justificativa é simples: "o homem era superior, e portanto cabia a ele exercer a autoridade" (ARAÚJO, 2002, p. 46). São Paulo, na Epístola aos Efésios, esclarece: "As mulheres estejam sujeitas aos seus maridos como ao Senhor, porque o homem é a cabeça da mulher, como Cristo é a cabeça da Igreja, [...] como a Igreja está sujeita a Cristo, assim o estejam também as mulheres a seus maridos em tudo" (EFÉSIOS, 5:22-24).

Perrot (2006) confirma que tudo isso se deve ao que é encontrado no livro de Gênesis, devido à potência sedutora de Eva: "A mulher, origem do mal e da infelicidade, potência noturna, força das sombras, rainha da noite" ( $p$. 168). Entretanto, ela garante que as mulheres não são só forças do mal. Elas também apresentam um lado maternal e benéfico. A pesquisa feminista contribuiu na reavaliação do poder das mulheres, mostrando a presença, a ação, a cultura e os poderes das mulheres. É necessário esclarecer que Perrot 
(2006) distingue poder e poderes. Quanto ao poder, ela afirma que é um termo polissêmico, que apresenta uma conotação política, designando uma figura central, supostamente masculina. Poderes, as mulheres detêm, tanto no privado, no familiar e na sociedade civil, pois elas "[r]einam no imaginário dos homens, preenchem suas noites e ocupam seus sonhos" (PERROT, 2006, p. 167).

Diante do exposto, passa-se a compreender melhor a dominação masculina e como ocorre a construção social e histórica dos corpos. Para Xavier (2007), é na interação com alguém ou alguma coisa que os corpos devem ser vistos. O sexo feminino carrega o peso de ser um corpo subalterno devido a questões culturais produzidas através dos tempos. Segundo Bourdieu, a diferença biológica entre o corpo masculino e o corpo feminino é a responsável pelas diferenças de gênero socialmente construídas. Essas diferenças estão "na ordem das coisas" (BOURDIEU, 1999, p.17), de forma objetivada, na casa, por exemplo, em todo o mundo social e de forma já incorporada nos corpos e na cultura das pessoas. Nas palavras do Bourdieu (1999, p. 15-16):

A constituição da sexualidade [...] nos fez perder o senso da cosmologia sexualizada, que se enraíza em uma tipologia sexual do corpo socializado, de seus movimentos e seus deslocamentos, imediatamente revestidos de significação social - o movimento para o alto sendo, por exemplo, associado ao masculino, como a ereção, ou a posição superior no ato sexual.

Conforme o autor, as situações são definidas através da divisão das coisas e das atividades segundo a oposição masculino/feminino, superior/inferior, alto/baixo, direita/esquerda, em cima/embaixo, etc., o que é considerado para muitos análogo aos movimentos do corpo. Também está socialmente construída a ideia de potência sexual do homem, ou o que se espera "de um homem que seja realmente um homem" (BOURDIEU, 1999, p. 20). Assim, explica-se porque a sociedade é regulada pela ordem patriarcal e ditatorial e porque o corpo feminino é, na maioria das vezes, representado de forma subalterna. Novamente, recorre-se a Bourdieu para explicitar que o 
corpo é responsável pela construção da diferença entre os sexos (1999, p. 1920):

O mundo social constrói o corpo como realidade sexuada e como depositário de princípios de visão e de divisão sexualizantes. Esse programa social de percepção incorporada aplica-se a todas as coisas do mundo e, antes de tudo, ao próprio corpo, em sua realidade biológica: é ele que constrói a diferença entre os sexos biológicos, conformando-a aos princípios de uma visão mítica do mundo, enraizada na relação arbitrária de dominação dos homens sobre as mulheres, ela mesma inscrita, com a divisão do trabalho, na realidade da ordem social.

Conforme visto, essa dominação dos homens sobre as mulheres é questão social, histórica e cultural. O sexo é uma pequena diferença que nos classifica como homens ou mulheres; mas veremos que não é só essa pequena diferença que perdura. Para falar do sexo das mulheres, Michelle Perrot (2008) alude a uma tela de Courbet L'Origine Du monde, que está hoje no Museu d'Orsay. Kalil Bey, ex-embaixador turco, colecionador de telas eróticas, guardou essa tela secretamente como se fosse um escandaloso tesouro. $\mathrm{Na}$ verdade era mesmo, pois seu criador desenhou uma vulva entreaberta de uma mulher.

Até mesmo entre as próprias mulheres existe ainda certo pudor acerca do corpo e da sexualidade. A puberdade nas sociedades ocidentais é pouco celebrada. Percebe-se o silêncio, o segredo e o desconforto. Somente a partir de 1970 é que as mães passaram a falar com as filhas sobre o corpo, a menstruação, a higiene. Da mesma forma ocorre com a menopausa, que marca o fim da vida fértil, do período da feminilidade e da sedução. Se a sociedade tende a marginalizar o idoso em geral, as mulheres sofrem muito mais, pois a cultura dominante atribui determinados padrões de beleza e de juventude. Sob essa ótica, a vida das mulheres mais idosas acaba se transformando em frustração e sofrimento.

É através do corpo que se revela a velhice, e a relação com o tempo, geralmente, é vivida de maneira distinta, conforme um maior ou menor grau de transformação do corpo ou segundo a cultura dominante. É "um fenômeno biológico com consequências psicológicas" (XAVIER, 2007, p. 86). Simone de 
Beauvior afirma: já que o destino da mulher é ser, aos olhos do homem, um objeto erótico, ao tornar-se velha e feia, ela perde o lugar que lhe é destinado na sociedade" (BEAUVIOR, 1990, p. 152). O fator social tem contribuição essencial no processo de envelhecimento.

Outra reflexão importante a ser realizada acerca do corpo feminino é o do viés da prostituição. O corpo das mulheres é um corpo dominado, reprimido: a prostituição, motivada pela miséria e pela solidão é acompanhada pela exploração do corpo e do sexo das mulheres. É um sistema antigo e quase universal, mas considerado e organizado de maneira diferente nas mais distintas sociedades, dependendo do valor dado à virgindade e à sexualidade. No Japão, as gueixas têm a missão de divertir os homens, pelo canto, pela dança, ocasionalmente pelo sexo. No Ocidente, a prostituição é mais estigmatizada e é considerada um símbolo da exploração das mulheres. "Um mercado no qual o corpo das mulheres é objeto e valor" (PERROT, 2008, p. 80).

Acerca da representação do sexo feminino, Perrot (2008) assegura que de Aristóteles a Freud, o sexo feminino era visto como um defeito, como se fosse uma fraqueza da natureza, marcado para a possessão, tanto por sua anatomia quanto por sua biologia. Mais tarde, os homens passam a cobiçar a virgindade das moças. Passa-se a discutir o prazer sexual feminino e, até hoje, discute-se o valor da maternidade. Entretanto, o universo da sexualidade feminina ainda é algo a ser explorado. "O sexo das mulheres é um poço sem fundo, onde o homem se esgota, perde suas forças e sua vida beira a impotência" (PERROT, 2008, p. 65). O que é condenado, especialmente pelas feministas, é a associação da oposição macho/fêmea com a oposição mente/corpo, responsável pela discriminação das mulheres. Simone de Beauvior afirma que o conceito do corpo feminino é um obstáculo a ser superado para que se chegue à igualdade.

Dessa forma, serão examinadas as obras A Doce Canção de Caetana e Eva Luna a partir do modo como nelas se opera o conceito de sexualidade e do corpo feminino. As questões acerca desses elementos em A Doce Canção de Caetana aparecem de forma muito mais extenuante do que em Eva Luna, pois o enredo daquele texto gira em torno da passagem do tempo para as 
personagens, da velhice dos corpos, da prostituição e da própria condição feminina. No texto de Isabel Allende, é possível aplicar esse estudo em determinadas situações vividas pela protagonista Eva. Entretanto, o que é similar nas duas obras é a forma como ocorre a representação dos corpos das protagonistas: elas não representam o tempo todo corpos subalternos ou discriminados. Suas atitudes conseguem mudar sua condição de dominadas. Tanto Caetana quanto Eva são batalhadoras e corajosas, conhecem e interagem com outras pessoas, extraem de suas dificuldades força para superar os obstáculos e realizar seus sonhos. O corpo das duas mulheres não se torna imobilizado pelo "adestramento imposto pelo patriarcado" (XAVIER, 2007, p. 80-81).

Alguns aspectos do romance Eva Luna representam o corpo subalterno porque em determinados momentos, especialmente na infância, a protagonista sofre devido à fome, carência, maus tratos. Eva não tem uma vida de criança normal que tem lazer ou que pode dedicar seu tempo aos estudos e às brincadeiras (ALLENDE, 1997, p. 28-29):

No tuve juguetes visibles, aunque en verdad todo lo que había en la casa servía para mis juegos. En el día no había momentos de descanso, se consideraba vergonzoso mantener las manos quietas. Junto a mi madre, yo fregaba las maderas del suelo, tendía la ropa a secar, picaba las verduras y a la hora de la siesta intentaba tejer y bordar, [...].

Quando fica órfã, precisa passar, limpar, cozinhar, servir. Eva passa a peregrinar de casa em casa para trabalhar. Servia aos outros, muitas vezes, de forma escrava. Um de seus patrões se excedia em suas ordens. Eva precisava até limpar suas fezes, que não eram feitas no banheiro (ALLENDE, 1997, p. 107):

Frente al escritorio de jacarandá se alzaba el antiguo sillón de felpa obispal, de brazos y patas doradas, con un orificio en el asiento. Allí se instalaba el patrón a satisfacer los apremios de su naturaleza, cuyo producto iba a pararen un recipiente de loza colocado debajo. [...] Al concluir tiraba del cordón de una campana que repicaba en toda las casa como un anuncio de catástrofe y yo, furiosa, subía a retirar la bacinilla sin comprender porque ese hombre no usaba el baño como cualquier persona normal. 
Já a personagem Caetana, no passado, renunciou a uma vida tranquila financeiramente; mas de dominação que o amante Polidoro the ofereceu $e$ fugiu de Trindade em busca de novos sonhos. Agora, Caetana exige tratamento de atriz do antigo amante. Ela não se submete ao poder patriarcal e social imposto. "Caetana se tornara o tendão de Aquiles de Polidoro. Ela era o pedaço do corpo que a mãe do herói, na ânsia de resguardá-lo, esqueceu de mergulhar na tina com a água preparada pelos deuses" (PIÑON, 1987, p. 134). A atriz representa o corpo liberado, longe de sofrer com a dominação do corpo masculino. Ao contrário, é o corpo de Caetana que exerce dominação sobre Polidoro. É ela que reina em seu imaginário. "A lingerie que trajava permitiu a Polidoro sonhar com suas formas". "A única dama que ele aguardou por vinte anos" (PIÑON, 1987, p. 135).

Os demais corpos femininos em $\mathbf{A}$ doce canção de Caetana são vítimas da opressão do tempo e dos homens de Trindade. As prostitutas da Casa da Estação não têm o direito de frequentar certos lugares. São proibidas de entrar no hotel Palace, não são convidadas para festas. O determinismo sexual prega a submissão feminina aos interesses sexuais dos homens da cidade (PIÑON, 1987, p. 141):

- Que mania é esta de dizer se é bom ou ruim! Para nós é sempre ruim. Vê se eles nos deixam entrar no Palace ou nos convidam para uma festa de casamento ou de batizado. Esse machos só nos chamam mesmo para trepar, e isso enquanto 0 corpo servir.

Elas sabem que têm valor enquanto forem jovens; quando idosas, se transformarão em cartas fora do baralho. Na verdade, elas já são corpos reprimidos, dominados porque exercem o papel de prostitutas. Além disso, passam a sofrer com a passagem do tempo, com a velhice; agora se consumirá sua discriminação: são prostitutas e velhas, não têm uma profissão "digna", não têm dinheiro, não estudaram. São conscientes de que não haverá mais espaço para elas na sociedade. Representam corpos triplamente discriminados e subalternos: são do sexo feminino, prostitutas e velhas.

Assim também, Eva é marcada pela discriminação: não pôde estudar, é pobre, é mulher. "-Si fueras hombre, irías a la escuela y después a estudiar 
para abogado" (ALLENDE, 1997, p. 48). Eva é educada de forma rústica por Elvira que, ou por falta de conhecimento ou por pudor, não falava claramente com a garota sobre sexualidade (ALLENDE, 1987, p. 71):

\begin{abstract}
Elvira me había advertido que con incuestionable claridad que los hombres tienen entre las piernas un monstruo tan feo como una raíz de yuca, por donde salen los niños en miniatura, se meten en la barriga de las mujeres y allí se desarrollan. No debía tocar esas partes por ningún motivo, porque el animal dormido levantaría su horrible cabeza, me saltaría encima y el resultado sería una catástrofe; pero yo no la creía, eso sonaba como otra de sus estrafalarias divagaciones.
\end{abstract}

Eva cresce e aprende as questões acerca da sexualidade de forma inocente. "El patrón solo tenía una lombriz gorda y lamentable, siempre mustia, de la cual jamás salió nada parecido a un bebé, al menos en mi presencia. Era similar a su pulposa nariz y descubrí entonces [...] la relación estrecha entre el pene y la nariz" (ALLENDE, 1987, p. 71). Entretanto, com o passar do tempo, a escritora e narradora Eva Luna passa a questionar os valores femininos diante das injustiças da sociedade patriarcal e ditatorial da época. Por meio da palavra, Eva passa de um corpo subalterno para um corpo liberado. Em troca de ajudas e atenções, Eva escreve. "Me acurruqué entre los papeles y le ofrecí un cuento en pago de tantas y tan finas atenciones (ALLENDE, 1987, p. 65).

Da mesma forma, as prostitutas em A Doce Canção de Caetana assumem uma nova postura ao tentar concretizar a identidade de atriz, o que exige novas performances sociais, por isso se distanciam da sexualidade. "Nada de trepar. Vivemos agora em função da arte. PIÑON, 1987, p. 266). A preocupação das Três Graças e de Gioconda não é mais agradar aos homens na cama. A condição de "macho", que para eles era mostrada através do sexo, muitas vezes pode ser motivo de questionamento. Diana "[a]bominava o homem de sexo desassossegado, com pressa de meter-se em sua vagina só pelo temor de perder o tesão" (PIÑON, 1987, p. 270). “- Não fale, senão perco o tesão”. “- O homem broxou” (PIÑON, 1987, p. 320). A condição de superioridade representada pelo poder sexual parece não ser verdadeira em algumas passagens do texto. Agora, a tarefa daquelas mulheres passa a ser outra. Suas energias estão voltadas para uma função mais ilustre. "- Reserve 
suas forças para o espetáculo, Sebastiana. Na qualidade de atriz você destinase agora a tarefas nobres" (PIÑON, 1987, p. 269).

O espetáculo no velho teatro Íris fracassa, pois o plano de Caetana de imitar Maria Callas ao som de uma vitrola antiga falha. O público percebe a fraude e a atriz foge novamente de Trindade. Está sem dinheiro, mas não busca consolo nos braços de seu antigo amante. "Caetana se mataria antes de depender da caridade de Polidoro" (PIÑON, 1987, p. 350). Entretanto, as Três Graças não conseguem se livrar das amarras da opressão, vítimas da sexualidade, continuam estigmatizadas como corpos dominados.

Como encontramos distintos elementos acerca da sexualidade e diversas representações do corpo feminino, é possível afirmar que não há uma forma fixa, mas que existe um corpo em permanente formação. É fato que "o corpo liberado vem surgindo com certa constância em nossa literatura de autoria feminina, o que não acontecia antes. O que representa uma tendência social que permite às mulheres viverem plenamente 'sua vocação de ser humano', sua sexualidade, [...]" (XAVIER, 2007, p. 196). Assim, as personagens protagonistas das duas obras passam por transformações, são resultado de um regime patriarcal e autoritário, mas a sexualidade não é pretexto para a manutenção de uma vida estática, de conformismo com a situação. Bem pelo contrário, seus corpos representam a liberação e a libertação.

\section{REFERÊNCIAS}

ALLENDE, Isabel. Eva Luna. Barcelona: Plaza \& Janés, 1997.

ANGELI, Daniela. Uma breve história das representações do corpo feminino na sociedade. Rev. Estud. Fem. v. 12, n. 2, Florianópolis, 2004. Disponível em <http://www.scielo.br/scielo.php?script=sci_arttext\&pid=S0104026X200400020 0017\&lng=en\&nrm=iso> < $\quad$ http://dx.doi.org/10.1590/S0104$026 \times 2004000200017>$. acesso em 15 out. 2011 às $14 \mathrm{~h}$. 
ARAÚJO, Emanuel. A arte da sedução: sexualidade feminina na Colônia. In: PRIORE, Mary Del. História das Mulheres no Brasil. (Org.). 6. ed. São Paulo: Contexto, 2002.

BEAUVIOR, Simone de. A velhice. Trad. Maria Helena franco Martins. 3. ed. Rio de Janeiro: Nova Fronteira, 1990.

BÍBLIA. 1982. A Bíblia Sagrada. Antigo e Novo Testamento. São Paulo: Edições Paulinas, 1982.

BOURDIEU, Pierre. A dominação masculina. Trad. Fernando Tomaz. Rio de Janeiro: Bertrand Brasil, 1999.

PERROT, Michelle. Os silêncios do corpo da mulher. In: MATOS, Maria zilda; SOIHET, Raquel (Orgs.). O corpo feminino em debate. São Paulo: UNESP, 2003.

. Os excluídos da história: operários, mulheres e prisioneiros. Trad. Denise Bottmann. Rio de Janeiro: Paz e Terra, 2006.

. Minha história das mulheres. Trad. Angela M.S. Corrêa. São Paulo: Contexto, 2008.

PIÑON, Nélida. A doce canção de Caetana. Rio de Janeiro: Record, 1987.

PRIORE, Mary Del. História das mulheres no Brasil (Org.). 6. ed. São Paulo: Contexto, 2002.

XAVIER, Elódia. Que corpo é esse? O corpo no imaginário feminino. Florianópolis: Ed. Mulheres, 2007. 